\title{
Parametric optimization of Nd:YAG laser microgrooving on aluminum oxide using integrated RSM-ANN-GA approach
}

\author{
Salila Ranjan Dixit ${ }^{1} \cdot$ Sudhansu Ranjan Das ${ }^{1} \cdot$ Debabrata Dhupal $^{1}$
}

Received: 12 October 2017 / Accepted: 5 October 2018 / Published online: 10 October 2018

(c) The Author(s) 2018

\begin{abstract}
Nowadays in highly competitive precision industries, the micromachining of advanced engineering materials is extremely demand as it has extensive application in the fields of automobile, electronic, biomedical and aerospace engineering. The present work addresses the modeling and optimization study on dimensional deviations of square-shaped microgroove in laser micromachining of aluminum oxide $\left(\mathrm{Al}_{2} \mathrm{O}_{3}\right)$ ceramic material with pulsed $\mathrm{Nd}$ :YAG laser by considering the air pressure, lamp current, pulse frequency, pulse width and cutting speed as process parameters. Thirty-two sets of laser microgrooving trials based on central composite design (CCD) design of experiments (DOEs) are performed, and response surface method (RSM), artificial neural network (ANN) and genetic algorithm (GA) are subsequently applied for mathematical modeling and multi-response optimization. The performance of the predictive ANN model based on 5-8-8-3 architecture gave the minimum error $(\mathrm{MSE}=0.000099)$ and presented highly promising to confidence with percentage error less than $3 \%$ in comparison with experimental result data set. The ANN model combined with GA leads to minimum deviation of upper width, lower width and depth value of $-0.0278 \mathrm{~mm}, 0.0102 \mathrm{~mm}$ and $-0.0308 \mathrm{~mm}$, respectively, corresponding to optimum laser microgrooving process parameters such as $1.2 \mathrm{kgf} / \mathrm{cm}^{2}$ of air pressure, $19.5 \mathrm{Amp}$ of lamp current, $4 \mathrm{kHz}$ of pulse frequency, $6 \%$ of pulse width and $24 \mathrm{~mm} / \mathrm{s}$ of cutting speed. Finally, the results have been verified by performing a confirmatory test.
\end{abstract}

Keywords Laser microgrooving $\cdot$ Aluminum oxide $\cdot$ RSM $\cdot$ ANN $\cdot$ GA

\section{Introduction}

Advanced engineering ceramics have been widely used in the development of critical components, because of their superior characteristics such as electrical insulation, high hardness, low thermal expansion coefficient, corrosion resistance, high temperature resistance and low weightto-strength ratio (Doloi et al. 2007; Hafezalkotob and Hafezalkotob 2016), and particularly these are extremely hard-to-cut materials due to extreme brittleness. Owing to these complexities, the task to machine a component with deterministic precision becomes challenging. In the recent

Sudhansu Ranjan Das

das.sudhansu83@gmail.com

Salila Ranjan Dixit

salila.simple@gmail.com

Debabrata Dhupal

debabratadhupal@gmail.com

1 Department of Production Engineering, Veer Surendra Sai University of Technology, Burla, Odisha 768018, India past, laser beam machining (LBM) has been explored as an effective and emerging process for shaping ceramic materials. Pulsed laser is efficient for micromachining of hard-to-cut material because of low pulse width with high peak power. Nd:YAG laser beam emits light or photons of shorter wavelength generating high power densities and small, focused spot diameter better than the benefits offered by conventional $\mathrm{CO}_{2}$ laser. Laser microgrooving operation considers various micromachining input process parameters like laser power, pulse width, spot size and cutting speed, which are quite compatible as well as in close agreement with derived energy equation of heat transfer (Chryssolouris 1991; Olsen and Alting 1995). Assist gas pressure also substantially affects the shape, geometry and dimension of cut during laser micromachining operation (Darwish et al. 2017; Farooq and Kar 1998). During square microgrooving operation, maintaining of squareness and depth is an essential factor to inherent focusing quality of laser machining process. The above-mentioned parameters are usually adjusted and utilized for machining to give the quality of microgroove desired, but this consumes exhaustive amounts of time and 
effort, and still there is scope of researchers for good-quality microgrooving conditions. Moreover, to improve its machining performance effectively and efficiently, the optimized process parameters and predictive models are also essentially required.

When manufacturers deal with multiple conflicting objectives, modeling technique helps in enhancing the efficacy of machining process. Although many theoretical models involve simplifications, assumptions and approximations for approaching real machining process, they do not consider any undesirable deficiency in the process. Therefore, analytical solutions cannot be easily extended to practical usage (Davim 2001), and for this reason, adequate modeling is essential to do quality predictions in a function of cutting conditions. The model development by RSM and ANN is a convenient method for the product as well as process improvement and has received a considerable attention by the researchers in the last two decades.

However, due to the complex behavior of the machining processes, where a few distinctive and contradictory objectives must be simultaneously optimized, at the same time the mono-objective optimization techniques do not permit to find the comprehensive optimal cutting conditions value which fulfills all the execution attributes in machining; hence, the multi-objective optimization has turned into an increasingly important and challenging task (Khamel et al. 2012; Das et al. 2015). Indeed, it offers most prominent measure of data with a specific end goal to make a decision on choosing process parameters in machining process. Earlier researchers have applied different optimization techniques, like Taguchi method (Shivade and Shinde 2014), Grey relation analysis (Kumar A, Soota T, Kumar J Optimisation of wire-cut EDM process parameter by Grey-based response surface methodology. J Ind Eng Int. https://doi.org/10.1007/s4009 2-018-0264-8), desirability function (Kumar et al. 2015), for finding out the optimal process parameter values. Researchers are now focusing on employment of artificial intelligence (AI) techniques, viz. ANN, GA and fuzzy logic (Markopoulos et al. 2016; Qian X, Ma Y, Feng H Collaboration space division in collaborative product development based on a genetic algorithm. J Ind Eng Int. https://doi.org/10.1007/ s40092-018-0257-7; Moghaddam and Kolahan 2016), for the process modeling and optimization of manufacturing processes which are expected to overcome some limitations of conventional process modeling techniques. Due to the ability to find a set of trade-off solutions in a single simulation run, inclination toward the adaptation of AI-based optimization methods especially evolutionary multi-objective optimization (EMO) algorithm shows a growing interest not only to control and predict the behavior of the phenomenon, but also to accomplish a common goal of improving machining performance. Various researchers have employed methods which include statistical and analytical approaches for mathematical modeling (Ciurana et al. 2009; Kibria et al. 2013; Mishra and Yadava 2013; Madić et al. 2015) in order to predict the responses and for multi-response optimization (Dhupal et al. 2008; Wang et al. 2016; Giorleo et al. 2016) in order to control the process parameters during laser micromachining process. Recently, Shivakoti et al. (2017) highlighted the use of fuzzy TOPSIS method for the selection of optimal laser micromarking process parameters to improve the marking performance on high strength temperature resistance material such as gallium nitride $(\mathrm{GaN})$. In an another study Kalita et al. (2017) performed an investigation with same workpiece material for optimization of process parameters in laser beam micromarking using genetic algorithm (GA) and particle swarm optimization (PSO). The results showed that there is a close agreement between the GA parameter settings with PSO results. Kibria et al. (Kibria et al. 2014) modeled the relationship between the laser microturning process parameters (laser power, pulse frequency, rotational speed, air pressure and feed rate) and quality characteristics using ANN and performed multiobjective optimization using RSM in order to achieve the desired surface roughness and minimum depth deviation of turned part. Mukherjee et al. (Mukherjee et al. 2013) used artificial bee colony (ABC) algorithm for parametric optimization of two different Nd:YAG laser beam micromachining processes (microdrilling and microgrooving).

From the existing literature, most of the studies are on laser micromachining, viz. microdrilling (Biswas et al. 2010; Kuar et al. 2012; Nandi and Kuar 2015; Biswas et al. 2015; Zhang et al. 2015), microturning (Dhupal et al. 2008; Kibria et al. 2010, 2012, 2013; Hao et al. 2018), micromilling (Campanelli et al. 2013; Mohammed et al. 2017; Darwish et al. 2017; Yang et al. 2018) and micromarking (Shivakoti et al. 2017; Kalita et al. 2017; Peter et al. 2013; BrihmatHamadi et al. 2017); work in the field of laser microgrooving (Dhupal et al. 2007; Kuar et al. 2008) is very limited. Laser microgrooving is based on the interaction of a laser beam with the workpiece surface, non-uniform melting and ejection of material from the groove walls, and laser power reduction, as the beam propagates into the groove, can be identified as a cause for the variation in lower width and depth formation which is of prime importance to enhance the product quality. With the intention of achieving goodquality microgroove machined surface and better dimensional accuracy on alumina ceramic workpiece, intensive research is needed. Also, an extensive research work is much needed to develop a technology guidance for laser microgrooving of such a useful material for modern manufacturing industries. Moreover, appropriate combination and utilization, along with proper adjustment of pre-cited machining parameters, are of prime importance for acquiring good grade of microgroove, which is a challenging task as it consumes precious time and effort due to the dynamic 
Fig. 1 Schematic diagram of Nd:YAG laser machining system
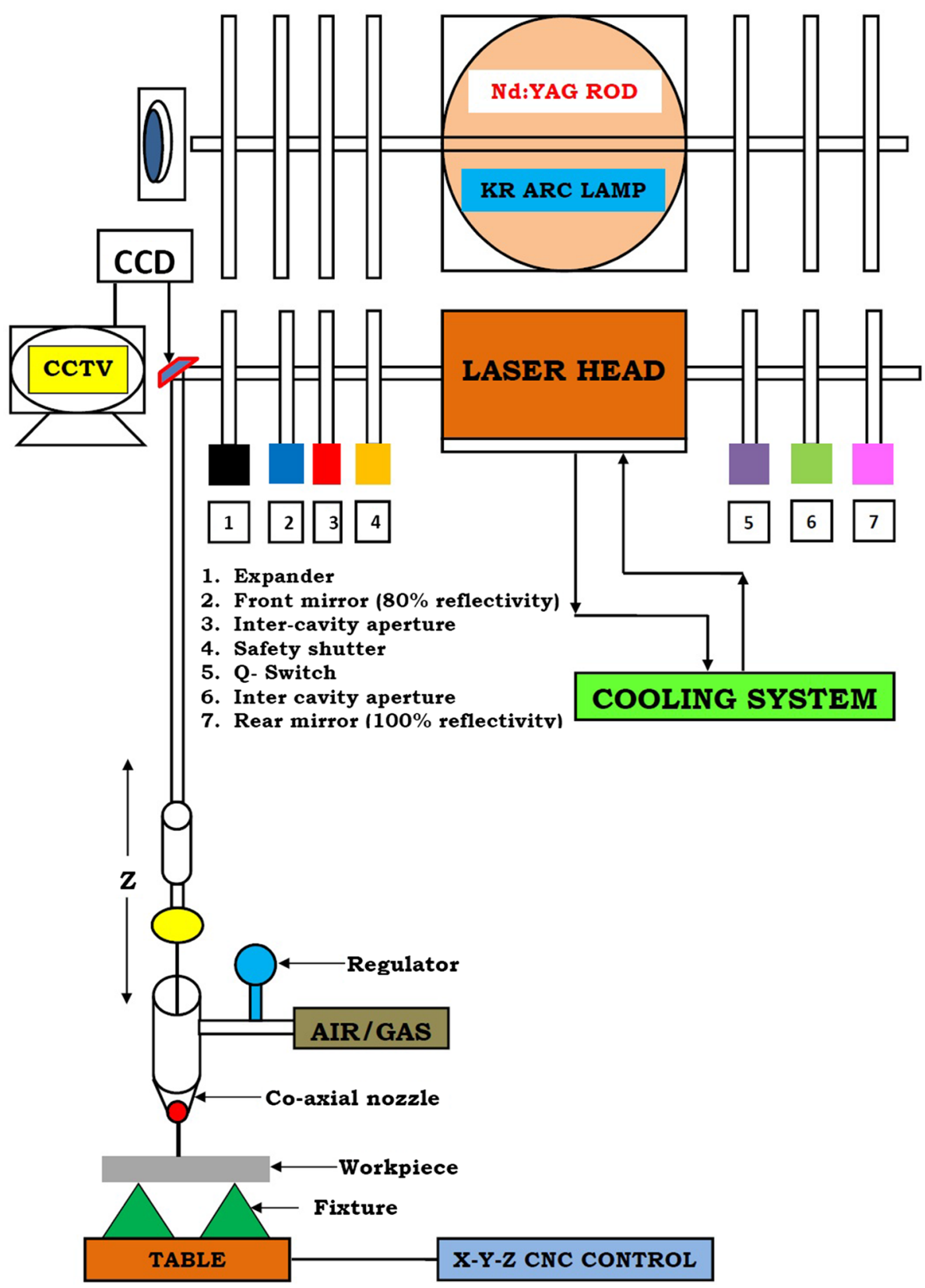

behavior of the laser micromachining process. Yet almost no systematic study has been reported in laser microgrooving operation that would ensure scope for researchers, and also no method currently results in the same level of efficiency for all processes. The novelty aspect of the present study focuses on the development of computational as well as empirical models and multi-response parametric optimization in microgrooving of alumina $\left(\mathrm{Al}_{2} \mathrm{O}_{3}\right)$ ceramic material through Nd:YAG laser treatment. Particularly, design of experiments (DOEs), response surface methodology (RSM), artificial neural network (ANN) and genetic algorithm (GA) have been applied to process improvement. The following dimensional deviations of the microgroove are addressed: upper width deviation, lower width deviation and depth deviation. The manuscript is arranged in the following form: "Introduction" section contains a brief overview of the motivation of the problem and shows the updated progress. "Experimental setup and procedure" section provides a brief description of the experimentation process, the material and the methods involved. "Results and discussion" section critically discusses the results obtained. The statistical analysis of the experiments and formation of the mathematical model are covered in section "Results and discussion." This section also highlights the use of ANN and GA as a suitable optimization technique for the current problem. Additionally, the final part of the manuscript derives conclusions based on the study. 


\section{Experimental setup and procedure}

Microgrooving experiments were conducted on $\mathrm{TEM}_{00}$ operating mode using computer numerical control (CNC) pulsed Nd:YAG laser machining system (model: SLTSP2000, make: SLT Ltd.) consisting of various subsystems. For experimentation, the laser beam (focused by the lens with focal length of $50 \mathrm{~mm}$ ) was set at workpiece surface as the focal plane which resulted in laser beam spot size of nearly $0.1 \mathrm{~mm} . \mathrm{Al}_{2} \mathrm{O}_{3}$ flat plate was subjected to microgrooving by multiple laser pulses using Nd:YAG laser treatment with actual peak power moving between 0.7 and $5 \mathrm{~kW}$. The compressed as well as regulated gas (air) is supplied into a fine coaxial nozzle to allow the grooving as per the experimental design. The movement of lens is controlled by the $\mathrm{CNC} \mathrm{Z}$-axis controller unit to attain the desired height (here, depth) of the microgroove. Figure 1 shows the schematic layout of the experimental setup for Nd:YAG laser machining unit. Figure 2 presents the pictorial view of a cut, showing shape and geometry to be produced by laser microgrooving. Multi-sawing software is used to generate square microgroove of size $200 \times 200 \times 200$ micron by setting zero taper angle. Prior to machining, the location of workpiece and focusing condition on workpiece surface were observed as well as checked by charged coupled device (CCD) camera including CCTV monitor in order to govern the position of laser beam spot precisely.

In the present work, response surface methodology (RSM) as well as artificial neural network (ANN) was considered for predictive modeling and genetic algorithm (GA) for multi-objective optimization by utilizing the observational data based on design of experiments (DOEs). Aluminum oxide $\left(\mathrm{Al}_{2} \mathrm{O}_{3}\right)$ ceramic plate of size $30 \mathrm{~mm} \times 30 \mathrm{~mm}$ is considered as a workpiece material for the experimentation due to its excellent material characteristics such as high electrical insulation, mechanical strength, wear as well as corrosion resistance which make the choice of components in a wide range of industrial and medical applications. The various leading properties of aluminum oxide are presented in Table 1.
In the current investigation, air pressure, lamp current, pulse frequency, pulse width and cutting speed are considered to be the process parameters which affect the response of interest in laser microgrooving operation, namely upper width deviation, lower width deviation and depth deviation. The input parameters have predominant impacts on the output criteria of laser microgrooving, as the lamp current combined with the pulse frequency provides the energy to remove the material and achieve the desired depth. The pulse width provides the accuracy of the microgroove shape. Air pressure is helpful to eject the debris from the narrow gap, and at the same time adequate cutting speed is required to generate a good-quality microgroove in sufficient time. Hence, the range of process parameters setting has been selected after performing some pilot experiments using fixed focal length and also by inspecting the workpiece for a through microgroove of acceptable quality. Also, a detailed literature survey has been performed to select the working range of process parameters. The identified process parameters and their associated levels are presented in Table 2. Using the selected factors (five) and parameters levels (five), a design matrix was formulated in conformance to central composite design (CCD) design of experiments (DOEs) associated with thirty-two (32) experimental runs. Design of experimental plan with actual value of process parameters,

Table 1 Properties of workpiece material (alumina, $\mathrm{Al}_{2} \mathrm{O}_{3}$ )

\begin{tabular}{lll}
\hline Properties & Units & Value \\
\hline Density & $\mathrm{gm} / \mathrm{cc}$ & 3.96 \\
Specific heat & $\mathrm{J} / \mathrm{kgk}$ & 775 \\
Thermal conductivity & $(\mathrm{cal} / \mathrm{s}) /\left(\mathrm{cm}^{2} \mathrm{C} / \mathrm{cm}\right)$ & $0.072-100{ }^{\circ} \mathrm{C}$ \\
& & $0.15-1000^{\circ} \mathrm{C}$ \\
Compressive strength & $\mathrm{MPa}$ & 2500 \\
Modulus of elasticity & $\mathrm{GPa}$ & 393 \\
Hardness & $\mathrm{GPa}$ & $1800, \mathrm{HB}-30$ \\
Fracture toughness & $\mathrm{MPa}-\sqrt{\mathrm{m}}$ & 4 \\
Sintering temperature & ${ }^{\circ} \mathrm{C}$ & 1600 \\
Melting temperature & ${ }^{\circ} \mathrm{C}$ & 2050 \\
\hline
\end{tabular}

Fig. 2 Pictorial view of square microgroove on flat surface

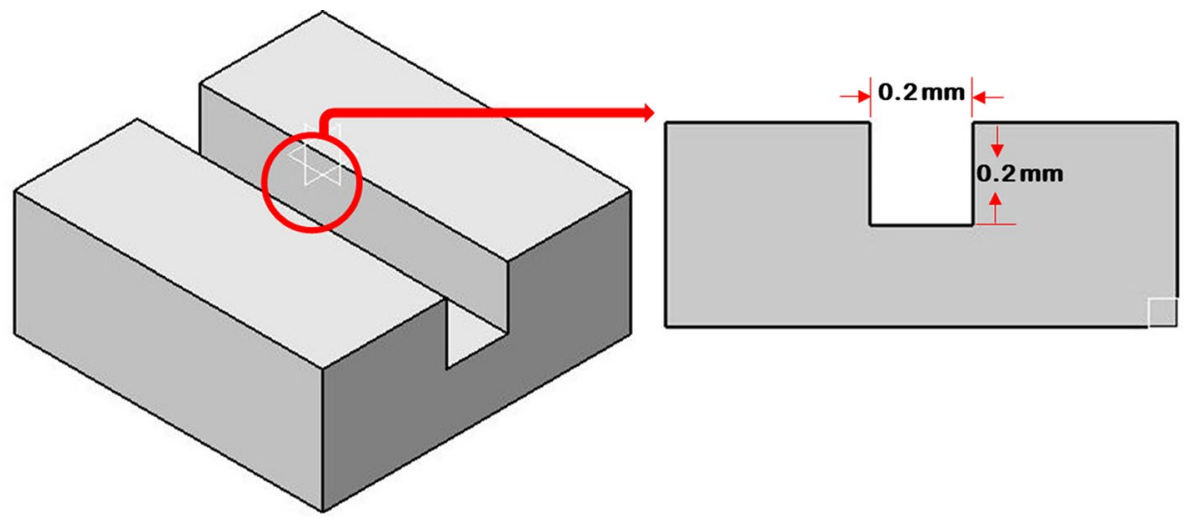


Table 3 Design of experimental plan and experimental results

\begin{tabular}{|c|c|c|c|c|c|c|c|c|c|c|c|}
\hline \multirow[t]{2}{*}{ Test no. } & \multicolumn{5}{|c|}{ Actual setting of parameters } & \multicolumn{3}{|c|}{ Dimensions of microgroove (mm) } & \multicolumn{3}{|c|}{ Dimensional deviations of microgroove (mm) } \\
\hline & $X_{1}$ & $X_{2}$ & $X_{3}$ & $X_{4}$ & $X_{5}$ & Upper width & Lower width & Depth & $\begin{array}{l}\text { Upper width } \\
\text { deviation }\end{array}$ & $\begin{array}{l}\text { Lower width } \\
\text { deviation }\end{array}$ & Depth deviation \\
\hline 1 & 1.6 & 17.0 & 2 & 2 & 16 & 0.1967 & 0.1390 & 0.160 & -0.003 & -0.061 & -0.040 \\
\hline 2 & 0.8 & 22.0 & 2 & 2 & 16 & 0.2210 & 0.2020 & 0.200 & 0.021 & 0.002 & 0.000 \\
\hline 3 & 1.6 & 17.0 & 4 & 6 & 16 & 0.1840 & 0.1550 & 0.168 & -0.016 & -0.045 & -0.032 \\
\hline 4 & 1.6 & 22.0 & 4 & 6 & 24 & 0.2154 & 0.1910 & 0.212 & 0.0154 & -0.009 & 0.012 \\
\hline 5 & 0.8 & 17.0 & 4 & 2 & 16 & 0.1930 & 0.1280 & 0.162 & -0.007 & -0.072 & -0.038 \\
\hline 6 & 1.2 & 24.5 & 3 & 4 & 20 & 0.2330 & 0.2005 & 0.234 & 0.033 & 0.001 & 0.034 \\
\hline 7 & 1.2 & 19.5 & 3 & 4 & 28 & 0.2490 & 0.1620 & 0.209 & 0.049 & -0.038 & 0.009 \\
\hline 8 & 1.2 & 19.5 & 3 & 4 & 20 & 0.2210 & 0.1355 & 0.165 & 0.011 & -0.064 & -0.035 \\
\hline 9 & 1.2 & 19.5 & 3 & 4 & 20 & 0.2054 & 0.1525 & 0.176 & 0.005 & -0.047 & -0.024 \\
\hline 10 & 1.2 & 19.5 & 3 & 0 & 20 & 0.2137 & 0.1565 & 0.142 & 0.013 & -0.043 & -0.058 \\
\hline 11 & 1.6 & 22.0 & 4 & 2 & 16 & 0.2062 & 0.1495 & 0.164 & 0.006 & -0.050 & -0.036 \\
\hline 12 & 1.2 & 19.5 & 3 & 4 & 20 & 0.1950 & 0.1350 & 0.202 & -0.005 & -0.065 & 0.002 \\
\hline 13 & 0.4 & 19.5 & 3 & 4 & 20 & 0.1853 & 0.1295 & 0.164 & -0.014 & -0.070 & -0.036 \\
\hline 14 & 1.2 & 19.5 & 3 & 8 & 20 & 0.1792 & 0.1295 & 0.149 & -0.021 & -0.070 & -0.051 \\
\hline 15 & 0.8 & 22.0 & 4 & 2 & 24 & 0.1915 & 0.1365 & 0.185 & -0.008 & -0.063 & -0.015 \\
\hline 16 & 1.2 & 19.5 & 3 & 4 & 12 & 0.2090 & 0.1265 & 0.189 & 0.009 & -0.073 & -0.011 \\
\hline 17 & 0.8 & 17.0 & 4 & 6 & 24 & 0.2040 & 0.1135 & 0.159 & 0.004 & -0.086 & -0.041 \\
\hline 18 & 0.8 & 17.0 & 2 & 6 & 16 & 0.1956 & 0.1255 & 0.136 & -0.004 & -0.074 & -0.063 \\
\hline 19 & 1.6 & 22.0 & 2 & 6 & 16 & 0.1915 & 0.1745 & 0.193 & -0.008 & -0.025 & -0.006 \\
\hline 20 & 1.2 & 19.5 & 5 & 4 & 20 & 0.1996 & 0.1700 & 0.163 & -0.001 & -0.030 & -0.037 \\
\hline 21 & 1.2 & 19.5 & 3 & 4 & 20 & 0.2060 & 0.1430 & 0.155 & 0.006 & -0.057 & -0.045 \\
\hline 22 & 2.0 & 19.5 & 3 & 4 & 20 & 0.1995 & 0.1470 & 0.142 & -0.001 & -0.053 & -0.058 \\
\hline 23 & 1.2 & 19.5 & 3 & 4 & 20 & 0.1992 & 0.1420 & 0.142 & -0.001 & -0.058 & -0.057 \\
\hline 24 & 0.8 & 17.0 & 2 & 2 & 24 & 0.2040 & 0.1440 & 0.132 & 0.004 & -0.056 & -0.067 \\
\hline 25 & 0.8 & 22.0 & 4 & 6 & 16 & 0.2050 & 0.1425 & 0.228 & 0.005 & -0.057 & 0.028 \\
\hline 26 & 0.8 & 22.0 & 2 & 6 & 24 & 0.2370 & 0.1735 & 0.183 & 0.037 & -0.026 & -0.016 \\
\hline 27 & 1.6 & 22.0 & 2 & 2 & 24 & 0.2316 & 0.1700 & 0.205 & 0.032 & -0.030 & 0.005 \\
\hline 28 & 1.2 & 14.5 & 3 & 4 & 20 & 0.1940 & 0.1190 & 0.117 & -0.006 & -0.081 & -0.083 \\
\hline 29 & 1.6 & 17.0 & 2 & 6 & 24 & 0.1907 & 0.1255 & 0.120 & -0.009 & -0.074 & -0.080 \\
\hline 30 & 1.6 & 17.0 & 4 & 2 & 24 & 0.2160 & 0.1535 & 0.126 & 0.016 & -0.046 & -0.074 \\
\hline 31 & 1.2 & 19.5 & 1 & 4 & 20 & 0.2125 & 0.2091 & 0.170 & 0.012 & 0.009 & -0.030 \\
\hline 32 & 1.2 & 19.5 & 3 & 4 & 20 & 0.2067 & 0.1630 & 0.168 & 0.006 & -0.037 & -0.032 \\
\hline
\end{tabular}

Table 2 Process parameters and levels

\begin{tabular}{lllllll}
\hline Parameters & Unit & Levels & & & \\
\cline { 3 - 6 } & & -2 & -1 & 0 & 1 & 2 \\
\hline Air pressure $\left(X_{1}\right)$ & $\mathrm{kgf} / \mathrm{cm}^{2}$ & 0.4 & 0.8 & 1.2 & 1.6 & 2.0 \\
Lamp current $\left(X_{2}\right)$ & $\mathrm{Amp}$ & 14.5 & 17 & 19.5 & 22 & 24.5 \\
Pulse frequency $\left(X_{3}\right)$ & $\mathrm{kHz}$ & 1 & 2 & 3 & 4 & 5 \\
Pulse width $\left(X_{4}\right)$ & $\%$ & 0 & 2 & 4 & 6 & 8 \\
Cutting speed $\left(X_{5}\right)$ & $\mathrm{mm} / \mathrm{s}$ & 12 & 16 & 20 & 24 & 28 \\
\hline
\end{tabular}

measured responses and estimated deviation parameters are presented in Table 3. The different dimensional deviations (responses) of machined microgroove were measured by utilizing optical microscope (model: STM6, make: Olympus) at the magnification level of $10 \times$. Figure 3 shows the schematic layout of methodology followed in the current 

experimental setup and methodology proposed
Fig. 3 Schematic layout of

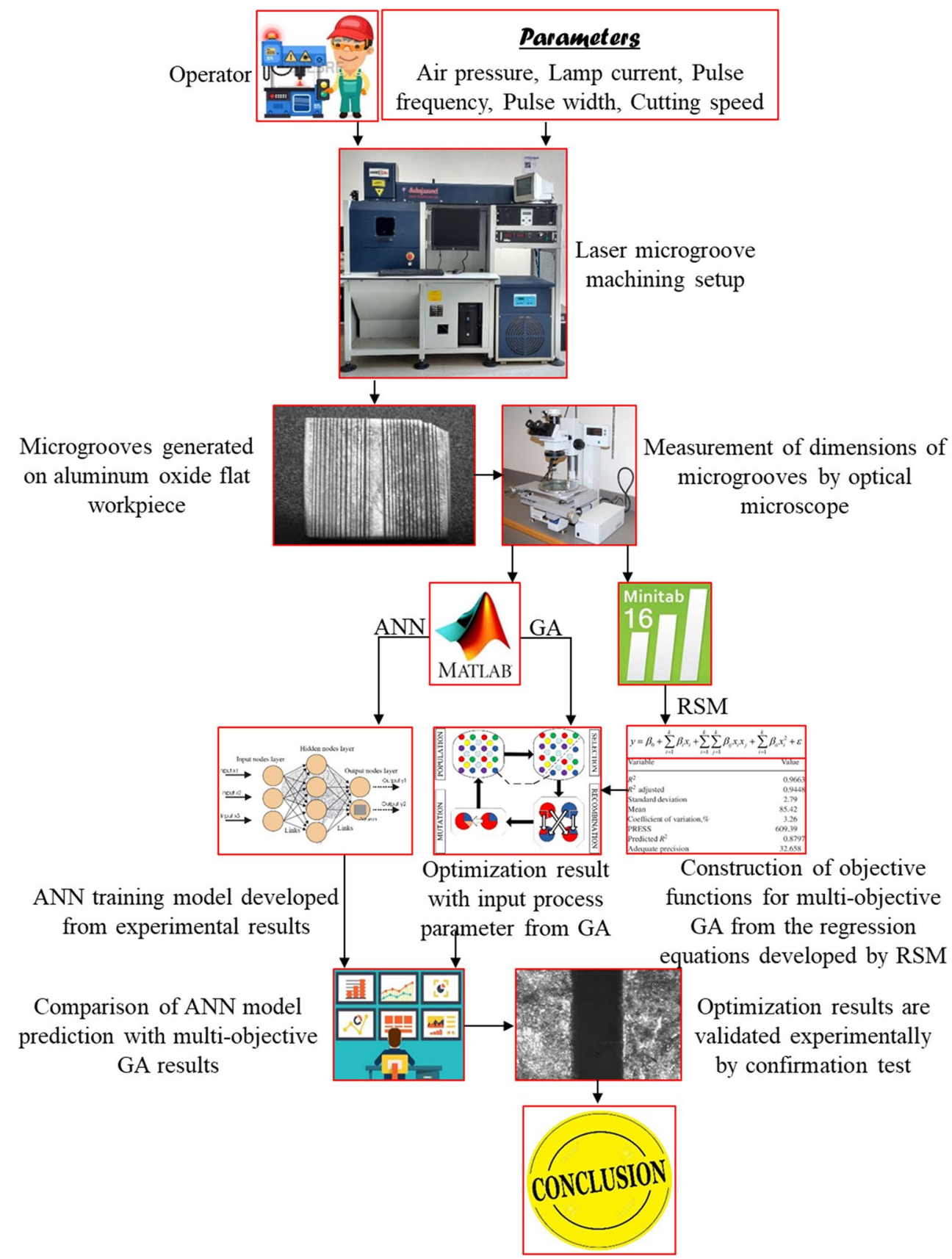

Results and discussion

deviation $\left(Y_{\mathrm{UWD}}\right)$, lower width deviation $\left(Y_{\mathrm{LWD}}\right)$ and depth deviation $\left(Y_{\mathrm{DD}}\right)$ are calculated as follows:

$Y_{\mathrm{UWD}}=Y_{\mathrm{AUW}}-Y_{\mathrm{TUW}}$

$Y_{\mathrm{LWD}}=Y_{\mathrm{ALW}}-Y_{\mathrm{TLW}}$

$Y_{\mathrm{DD}}=Y_{\mathrm{AD}}-Y_{\mathrm{TD}}$

where $Y_{\mathrm{AUW}}$ is the actual upper width, $Y_{\mathrm{TUW}}$ is target upper width, $Y_{\mathrm{ALW}}$ is actual lower with, $Y_{\mathrm{TLW}}$ is target lower width, $Y_{\mathrm{TD}}$ is target depth and $Y_{\mathrm{AD}}$ is the actual depth of microgroove.

\section{Model prediction using response surface methodology}

Response surface methodology is an integration of mathematical as well as statistical techniques, useful for modeling (Montgomery 2004) in various fields of engineering. In RSM, the second-order quadratic equation is the most common response model, and the approximation of the response function is obtained in the form of predictive variables by establishing the relationship between input parameters and 
Table 4 Results of ANOVA for dimensional deviations model

\begin{tabular}{|c|c|c|c|c|c|c|c|}
\hline Source & DOF & Sequential SS & Adjusted SS & Adjusted MS & $F$ & $P$ value & Remark \\
\hline \multicolumn{8}{|c|}{ (a) Upper width deviation, $Y_{U W D}$ model } \\
\hline Regression & 20 & 0.007120 & 0.007120 & 0.000356 & 6.26 & 0.002 & \multirow[t]{6}{*}{ Significant } \\
\hline Linear & 5 & 0.003599 & 0.000640 & 0.000128 & 2.25 & 0.121 & \\
\hline Interaction & 10 & 0.001786 & 0.001786 & 0.000179 & 3.14 & 0.037 & \\
\hline Square & 5 & 0.001735 & 0.001735 & 0.000347 & 6.11 & 0.006 & \\
\hline Residual error & 11 & 0.000625 & 0.000625 & 0.000057 & & & \\
\hline Total & 31 & 0.007745 & & & & & \\
\hline \multicolumn{8}{|c|}{ (b) Lower width deviation, $Y_{\mathrm{LWD}}$ model } \\
\hline Regression & 20 & 0.017356 & 0.017356 & 0.000868 & 6.04 & 0.002 & \multirow[t]{6}{*}{ Significant } \\
\hline Linear & 5 & 0.009493 & 0.001259 & 0.000252 & 1.75 & 0.203 & \\
\hline Interaction & 10 & 0.004190 & 0.004190 & 0.000419 & 2.92 & 0.047 & \\
\hline Square & 5 & 0.003672 & 0.003672 & 0.000734 & 5.11 & 0.011 & \\
\hline Residual error & 11 & 0.001580 & 0.001580 & 0.000144 & & & \\
\hline Total & 31 & 0.018935 & & & & & \\
\hline \multicolumn{8}{|c|}{ (c) Depth deviation, $Y_{\mathrm{DD}}$ model } \\
\hline Regression & 20 & 0.025359 & 0.025359 & 0.001268 & 4.61 & 0.006 & \multirow[t]{6}{*}{ Significant } \\
\hline Linear & 5 & 0.017916 & 0.002651 & 0.000530 & 1.93 & 0.169 & \\
\hline Interaction & 10 & 0.003912 & 0.003912 & 0.000391 & 1.42 & 0.286 & \\
\hline Square & 5 & 0.003531 & 0.003531 & 0.000706 & 2.57 & 0.089 & \\
\hline Residual error & 11 & 0.003027 & 0.003027 & 0.000275 & & & \\
\hline Total & 31 & 0.028386 & & & & & \\
\hline
\end{tabular}

desired responses (output). This is usually expressed in the following equation,

$Y=\beta_{0}+\sum_{i=1}^{k} \beta_{i i} X_{i}+\sum_{i=1}^{k} \beta_{i i} X_{i}^{2}+\sum_{i} \cdot \sum_{j} \beta_{i j} X_{i} X_{j}$

where $Y$ is the estimated response, $\beta_{0}$ is the constant, $\beta_{i}$, $\beta_{i i}$ and $\beta_{i j}$ represent the coefficients of linear, quadratic and cross-product terms, respectively. $X$ reveals the coded variables that correspond to the studied process parameters.

The empirical models in the form of quadratic regression equations to predict the various dimensional deviations of microgroove $\left(Y_{\mathrm{UWD}}, Y_{\mathrm{LWD}}\right.$ and $\left.Y_{\mathrm{DD}}\right)$ with air pressure $\left(X_{1}\right)$, lamp current $\left(X_{2}\right)$, pulse frequency $\left(X_{3}\right)$, pulse width $\left(X_{4}\right)$ and cutting speed $\left(X_{5}\right)$ are given below.

The upper width deviation $\left(Y_{\mathrm{UWD}}\right)$ is presented below in Eq. (5). Its coefficients of determination (experimental and adjusted) are $R^{2}=89.1 \%, R^{2}$ (adj.) $=87 \%$, respectively.

$$
\begin{aligned}
Y_{\mathrm{UWD}}= & 0.00448+0.01610 X_{1}-0.00657 X_{2}-0.00882 X_{3} \\
& +0.01477 X_{4}+0.00079 X_{5}+0.007279 X_{1}^{2} \\
& -0.00016 X_{2}^{2}-0.00971 X_{3}^{2}+0.02279 X_{4}^{2}-0.01381 X_{5}^{2} \\
& -0.01822 X_{1} X_{2}+0.00848 X_{1} X_{3}+0.00157 X_{1} X_{4} \\
& -0.00015 X_{1} X_{5}+0.01003 X_{2} X_{3}-0.00497 X_{2} X_{4} \\
& -0.01880 X_{2} X_{5}+0.01123 X_{3} X_{4}-0.02525 X_{3} X_{5} \\
& +0.01335 X_{4} X_{5}
\end{aligned}
$$

$R^{2}=89.1 \% \quad R^{2}$ (adj. $)=87 \%$

The lower width deviation $\left(Y_{\mathrm{LWD}}\right)$ is presented below in Eq. (6). Its coefficients of determination (experimental and adjusted) are $R^{2}=91.7 \%, R^{2}$ (adj.) $=90.1 \%$, respectively.

$$
\begin{aligned}
Y_{\mathrm{LWD}}= & -0.05375+0.03488 X_{1}-0.01356 X_{2} \\
& -0.00629 X_{3}+0.00521 X_{4}+0.01063 X_{5} \\
& +0.01026 X_{1}^{2}+0.04006 X_{2}^{2}-0.0649 X_{3}^{2} \\
& -0.00524 X_{4}^{2}-0.01124 X_{5}^{2}+0.029121 X_{1} X_{2} \\
& +0.01713 X_{1} X_{3}+0.00338 X_{1} X_{4}-0.00788 X_{1} X_{5} \\
& +0.02262 X_{2} X_{3}+0.01188 X_{2} X_{4}+0.04113 X_{2} X_{5} \\
& +0.00513 X_{3} X_{4}+0.02237 X_{3} X_{5}+0.01313 X_{4} X_{5} \\
R^{2}= & 91.7 \% \quad R^{2}(\text { adj. })=90.1 \%
\end{aligned}
$$

The depth deviation $\left(Y_{\mathrm{DD}}\right)$ is presented below in Eq. (7). Its coefficients of determination (experimental and adjusted) are $R^{2}=89.4 \%, R^{2}(\operatorname{adj})=.87.4 \%$, respectively.

$$
\begin{aligned}
Y_{\mathrm{DD}}= & -0.03239+0.05355 X_{1}+0.00489 X_{2}+0.00675 X_{3} \\
& -0.00405 X_{4}-0.00671 X_{5}+0.00972 X_{1}^{2}+0.00057 X_{2}^{2} \\
& -0.02018 X_{3}^{2}+0.03322 X_{4}^{2}-0.01293 X_{5}^{2}-0.01464 X_{1} X_{2} \\
& +0.01499 X_{1} X_{3}+0.02249 X_{1} X_{4}-0.00094 X_{1} X_{5} \\
& +0.04886 X_{2} X_{3}+0.00236 X_{2} X_{4}-0.02251 X_{2} X_{5} \\
& -0.00371 X_{3} X_{4}+0.00236 X_{3} X_{5}+0.01136 X_{4} X_{5} \\
R^{2}= & \left.89.4 \% \quad R^{2} \text { (adj. }\right)=87.4 \%
\end{aligned}
$$



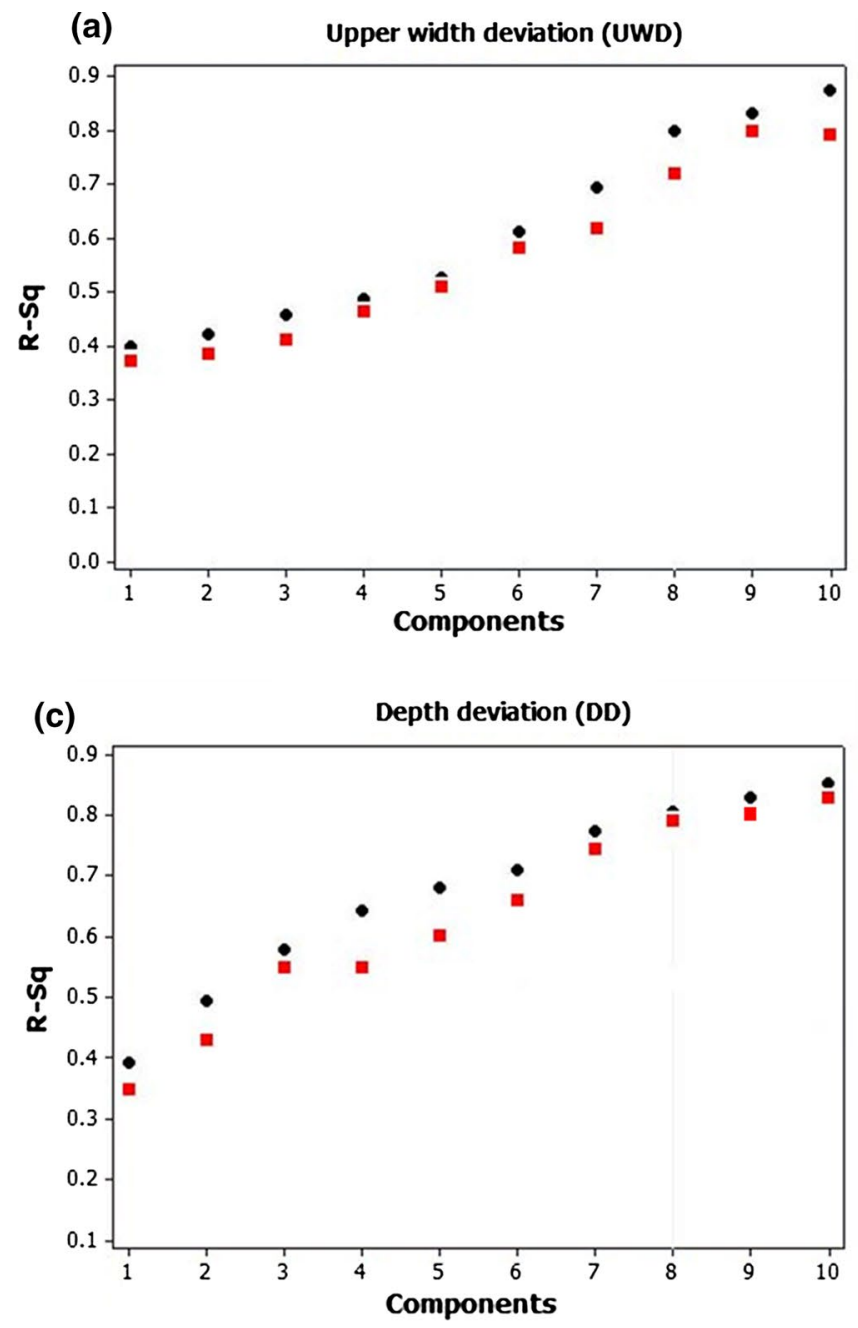

(b)

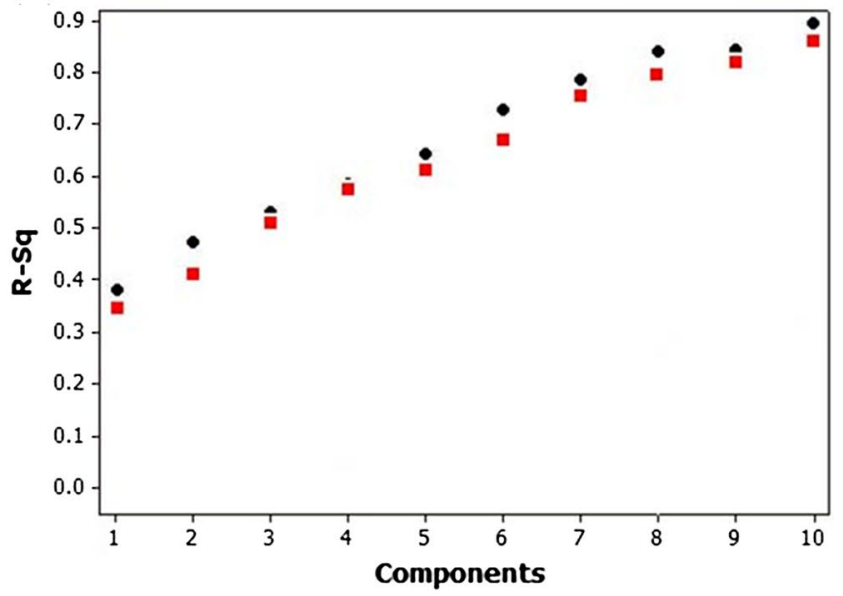

Fig. 4 PLSR model selection plot: a UWD; b LWD; $\mathbf{c}$ DD

Fig. 5 Developed 5-8-8-3 ANN architecture

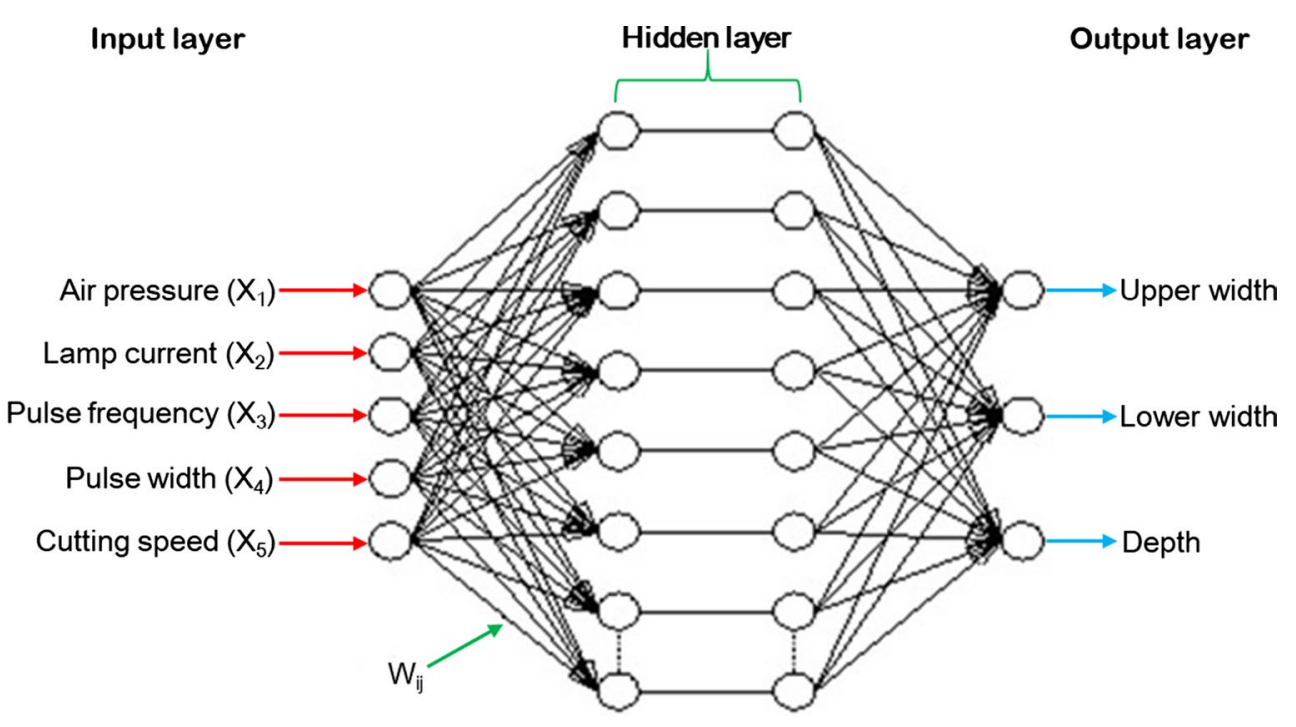




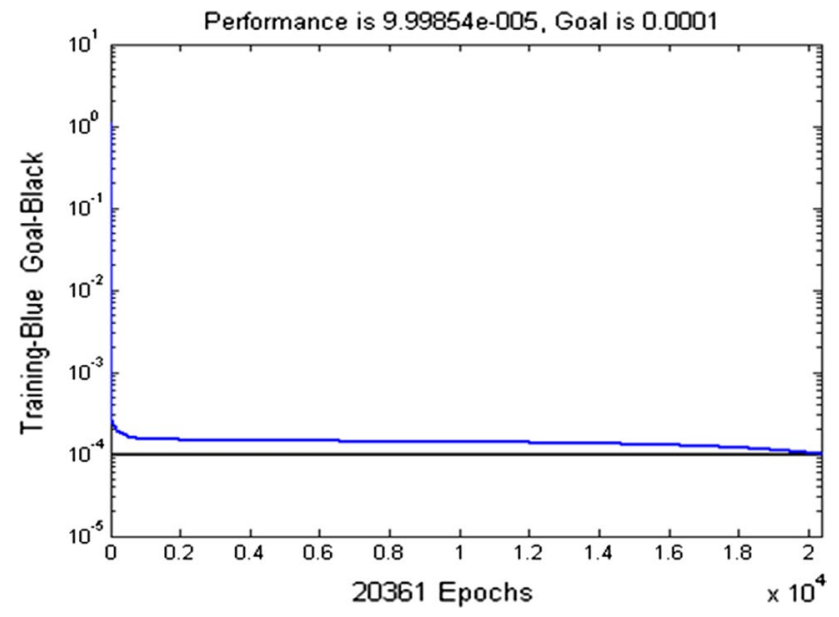

Fig. 6 Generation curve: MSE versus epochs during training and validation sessions

To avoid the misleading conclusion, the statistical significance as well as the adequacy of developed quadratic models for dimensional deviation criteria $\left(Y_{\mathrm{UWD}}, Y_{\mathrm{LWD}}\right.$ and $\left.Y_{\mathrm{DD}}\right)$ is checked by ANOVA based on $P$ value and $F$-value, as shown in Table 4. Generally, it is used to summarize the test of the regression equation (model), test of significance parameters and their interactions. If $P$ value of proposed model is less than 0.05 (95\% confidence level), it results in excellent statistical significance of model. From dimensional deviation models ANOVA for $Y_{\mathrm{UWD}}, Y_{\mathrm{LWD}}$ and $Y_{\mathrm{DD}}$, it is observed that mathematical models are significant as their $P$ value is less than 0.05 . Additionally, the models are adequate as model $F$ values 6.26, 6.04 and 4.61 to dimensional deviation criteria UWD, LWD and DD, respectively, which are more than $F$-table value (2.65) at $95 \%$ confidence level. Further, the effectiveness of the proposed models is performed with the help of $R^{2}$ value. When $R^{2}$ approaches to the value of 1 , implying the response models has closely resembled to the actual (experimental) data. In the present work, the $R^{2}$ values for the dimensional deviations of laser microgroove (UWD, LWD and DD) are $87 \%, 90.1 \%$ and $87.4 \%$, respectively, which indicate high statistical significance of the model and the goodness of fit for the model. It presents the good agreement existing between the predicted values and experimental values. The adjusted $R^{2}$ values for UWD, LWD and DD are $87 \%, 90.1 \%$ and $87.4 \%$, respectively, after observing the significant factors. Thus, the developed regression models can be successfully employed as objective functions for multiresponse optimization via genetic algorithm (GA). Further, the $R^{2}$-value of the developed models $\left(Y_{\mathrm{UWD}}, Y_{\mathrm{LWD}}\right.$ and $\left.Y_{\mathrm{DD}}\right)$ is analyzed for cross-validation with predicted $R^{2}$-value (denoted by "crossval") using model selection plot of partial least squares regression (PLSR), as shown in Fig. 4. The plot shows a good agreement between fitted- $R^{2}$ (blue circles) and predicted- $R^{2}$ (red squares) values, which indicates that the model has a greater predictive ability.

\section{Model prediction using artificial neural network}

Artificial neural network has been designed to mimic the linear order characteristics of structure interlinked nerve cells of human brain called biological neurons. Briefly, a group of certain inputs are mostly employed; each one designates the output of any other neuron. Each input is multiplied by a corresponding weight analogous to a synaptic strength, and these are summed up to determine the activation level of the neuron.

In this work, artificial neural network is applied to propose a model to train in order that a set of inputs to return the appropriated or useful set of outputs. ANN uses multilayer architecture consisting of different layers (input, hidden and output) for solving the nonlinear and complex problems with the help of feed-forward back-propagation training algorithm (Haykin 2002). Usually, in back-propagation NN, the net input is expressed as follows:

$Y_{j}=\sum_{i=1}^{i=n} w_{i j} x_{i}$

And the network output $\left(Z_{j}\right)$ of each neuron $i$ is obtained by processing the net input via an activation or transfer function (here, tangent hyperbolic type) as follows:

$Z_{j}=f\left(Y_{j}\right)=\frac{1-e^{-Y_{j}}}{1+e^{-Y_{j}}}$

where $Y_{j}$ net input is considered as linear combination of input variables in terms of weights, $j$ number of neurons,
Table 5 Check data set for testing ANN model and comparison results of predicted and measured dimensions of microgroove

\begin{tabular}{|c|c|c|c|c|c|c|}
\hline \multirow[t]{3}{*}{ Test no. } & \multicolumn{6}{|c|}{ Responses in $\mathrm{mm}$} \\
\hline & \multicolumn{2}{|l|}{ Upper width } & \multicolumn{2}{|c|}{ Lower width } & \multicolumn{2}{|l|}{ Depth } \\
\hline & ANN pred. & $\begin{array}{l}\text { Experimental } \\
\text { result }\end{array}$ & ANN pred. & $\begin{array}{l}\text { Experimental } \\
\text { result }\end{array}$ & ANN pred. & $\begin{array}{l}\text { Experi- } \\
\text { mental } \\
\text { result }\end{array}$ \\
\hline 1 & 0.18640 & 0.1840 & 0.1979 & 0.202 & 0.2130 & 0.2127 \\
\hline 2 & 0.2142 & 0.2137 & 0.1499 & 0.1525 & 0.1640 & 0.1621 \\
\hline 3 & 0.2031 & 0.2050 & 0.1279 & 0.1255 & 0.1168 & 0.12 \\
\hline
\end{tabular}


Table 6 Training data set for testing ANN model and comparison results of predicted and measured dimensions of microgroove

\begin{tabular}{|c|c|c|c|c|c|c|}
\hline \multirow[t]{3}{*}{ Sl. no. } & \multicolumn{6}{|c|}{ Responses (mm) } \\
\hline & \multicolumn{2}{|l|}{ Upper width } & \multicolumn{2}{|l|}{ Lower width } & \multicolumn{2}{|l|}{ Depth } \\
\hline & ANN pred. & $\begin{array}{l}\text { Experimental } \\
\text { result }\end{array}$ & ANN pred. & $\begin{array}{l}\text { Experimental } \\
\text { result }\end{array}$ & ANN pred. & $\begin{array}{l}\text { Experimental } \\
\text { result }\end{array}$ \\
\hline 1 & 0.1958 & 0.1967 & 0.1341 & 0.1390 & 0.1601 & 0.1600 \\
\hline 2 & 0.2215 & 0.2210 & 0.1534 & 0.1550 & 0.1932 & 0.2000 \\
\hline 3 & 0.2163 & 0.2154 & 0.1715 & 0.1910 & 0.1667 & 0.1680 \\
\hline 4 & 0.1206 & 0.1930 & 0.1262 & 0.1280 & 0.1524 & 0.1620 \\
\hline 5 & 0.2327 & 0.2330 & 0.1931 & 0.2005 & 0.2323 & 0.2343 \\
\hline 6 & 0.2131 & 0.2490 & 0.1515 & 0.1620 & 0.1688 & 0.2090 \\
\hline 7 & 0.2003 & 0.2210 & 0.1468 & 0.1355 & 0.1669 & 0.1650 \\
\hline 8 & 0.2003 & 0.2054 & 0.1534 & 0.1565 & 0.1758 & 0.1760 \\
\hline 9 & 0.2073 & 0.2062 & 0.1479 & 0.1495 & 0.1522 & 0.1420 \\
\hline 10 & 0.2003 & 0.1950 & 0.1468 & 0.1350 & 0.1609 & 0.1640 \\
\hline 11 & 0.2035 & 0.1853 & 0.1297 & 0.1295 & 0.1636 & 0.1640 \\
\hline 12 & 0.1789 & 0.1792 & 0.1348 & 0.1295 & 0.1517 & 0.1495 \\
\hline 13 & 0.2131 & 0.1915 & 0.1516 & 0.1365 & 0.1819 & 0.1850 \\
\hline 14 & 0.209 & 0.2090 & 0.1292 & 0.1265 & 0.1898 & 0.1893 \\
\hline 15 & 0.2039 & 0.2040 & 0.1114 & 0.1135 & 0.1605 & 0.1590 \\
\hline 16 & 0.1957 & 0.1956 & 0.1242 & 0.1255 & 0.1407 & 0.1367 \\
\hline 17 & 0.1918 & 0.1915 & 0.1714 & 0.1745 & 0.1946 & 0.1937 \\
\hline 18 & 0.1996 & 0.1996 & 0.1659 & 0.1700 & 0.1685 & 0.1630 \\
\hline 19 & 0.2003 & 0.2060 & 0.1468 & 0.1430 & 0.1669 & 0.1550 \\
\hline 20 & 0.2024 & 0.1995 & 0.1569 & 0.1470 & 0.1305 & 0.1420 \\
\hline 21 & 0.2003 & 0.1992 & 0.1468 & 0.1420 & 0.1669 & 0.1427 \\
\hline 22 & 0.2124 & 0.2040 & 0.1371 & 0.1440 & 0.1336 & 0.1327 \\
\hline 23 & 0.2371 & 0.2370 & 0.1396 & 0.1425 & 0.2295 & 0.2280 \\
\hline 24 & 0.2316 & 0.2316 & 0.1853 & 0.1735 & 0.1909 & 0.1832 \\
\hline 25 & 0.1937 & 0.1940 & 0.194 & 0.1700 & 0.2058 & 0.2057 \\
\hline 26 & 0.2035 & 0.1907 & 0.1234 & 0.1190 & 0.1229 & 0.1170 \\
\hline 27 & 0.215 & 0.2160 & 0.1589 & 0.1535 & 0.127 & 0.1260 \\
\hline 28 & 0.2151 & 0.2125 & 0.1861 & 0.2091 & 0.1698 & 0.1700 \\
\hline 29 & 0.2003 & 0.2067 & 0.1468 & 0.1630 & 0.1669 & 0.1683 \\
\hline
\end{tabular}

$n$ is the input parameters, $x_{i}$ is the input parameter $i$ of the network, $w_{i j}$ represents the synaptic weight to jth neuron in the output layer from the $i$ th neuron in the previous layer.

In this study, many network architectures were tried, prior to use the optimal neural network architecture of 5-8-8-3 (with the lowest MSE), which is shown in Fig. 5. The network consists of one input layer which has five neurons, two hidden layers which have eight neurons each and then output layer which have three neurons, respectively. For calculation of connection weights, we require a set of desired network output values which are sometimes referred to as training data set. The training data set of desired outputs generated utilizing experimental data set, as reflected in Table 3. In order to get a closed-form solution, MATLAB function feed-forward back-propagation neural network (TRAINGD) was used for training the data of the network, which has been widely used for prediction and optimization of various machining processes (Dhar et al. 2008; Dhupal et al. 2009; Somashekhar et al. 2010; Kuo et al. 2012; Dahbi et al. 2017; Behera et al. 2016). TRAINGD is a network training function which works in accordance with the gradient descent method that measures the output error, calculates the gradient of the error by adjusting as well as updating the weight variable repetitively in the direction of the negative gradient of the performance function and also reduces the mean square error (MSE) between expected data and training data set. The change in weight variables is given in Eq. (10).

$\Delta w_{i j}=-\eta \frac{\partial E}{\partial w_{i j}} Z_{j}$ 
Fig. 7 Graphical comparison of predicted ANN with measured a check data and $\mathbf{b}$ training data set of upper width
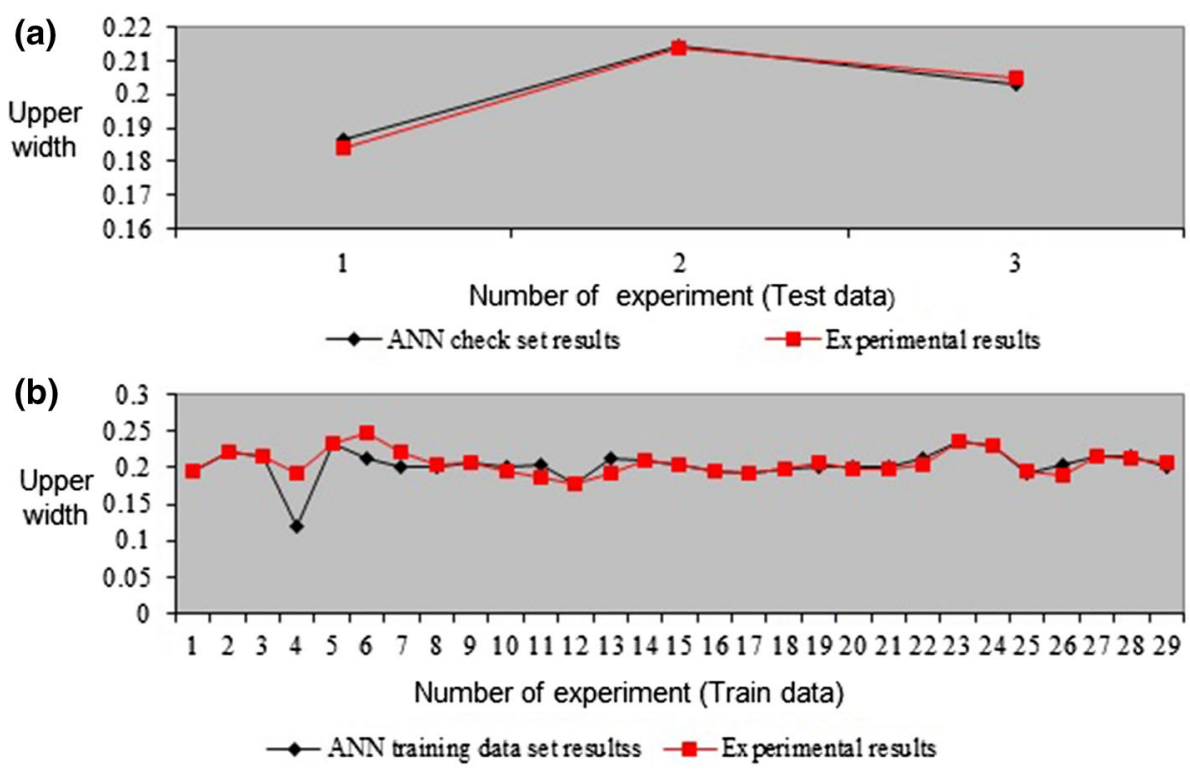

where $E$ is the mean square error estimating the gradient of the error, $\eta$ is the learning rate parameter generally controls the stability and rate of convergence of the ANN model. $\eta$ is considered as 0.0001 which is the constant value of learning rate. The MSE value calculated from the ANN is found to be 0.000099 . Figure 6 shows the data observed based on experiment of ANN training by means of MATLAB.

The data results obtained from experimentation and predicted data received by neural network were compared. Out of the 32 experimental data received in accordance with DOEs, 29 data were performed for training the neural network model. Subsequently, the remaining three (32-29) experimental results (check data) were compared with trained ANN model. Tables 5 and 6 show the comparison results between the experimental and ANN for 3 check data sets and 29 training sets, respectively. It can be seen that there is a close agreement between the ANN prediction and the experimental results. Figures 7, 8 and 9 compare the ANN prediction results for upper width, lower width and depth with the results of experiment for training and check data sets. It is observed that the variation in ANN and experimental result is under $3 \%$, which avoids the misleading
Fig. 8 Graphical comparison of predicted ANN with measured $\mathbf{a}$ check data and $\mathbf{b}$ training data set of lower width

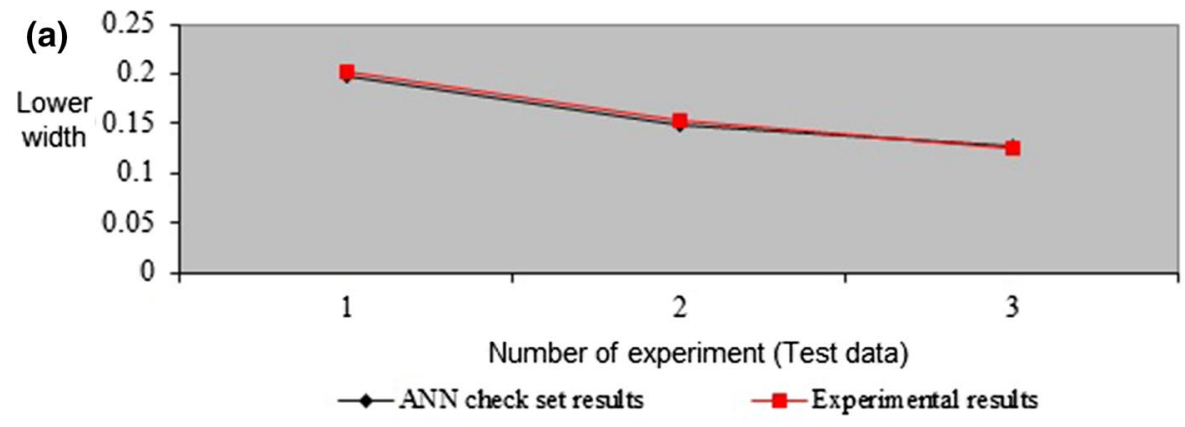

(b)

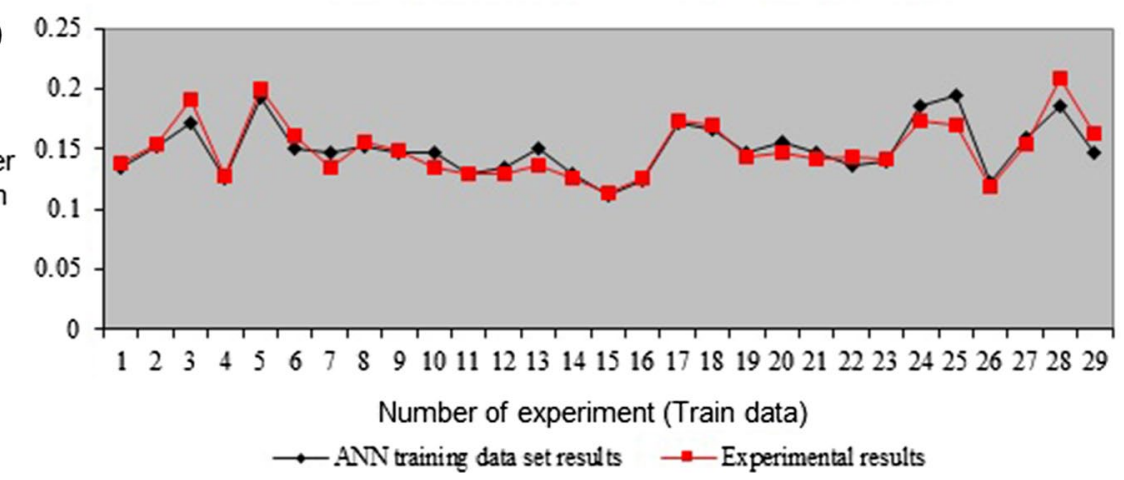


Fig. 9 Graphical comparison of predicted ANN with measured $\mathbf{a}$ check data and $\mathbf{b}$ training data set of depth
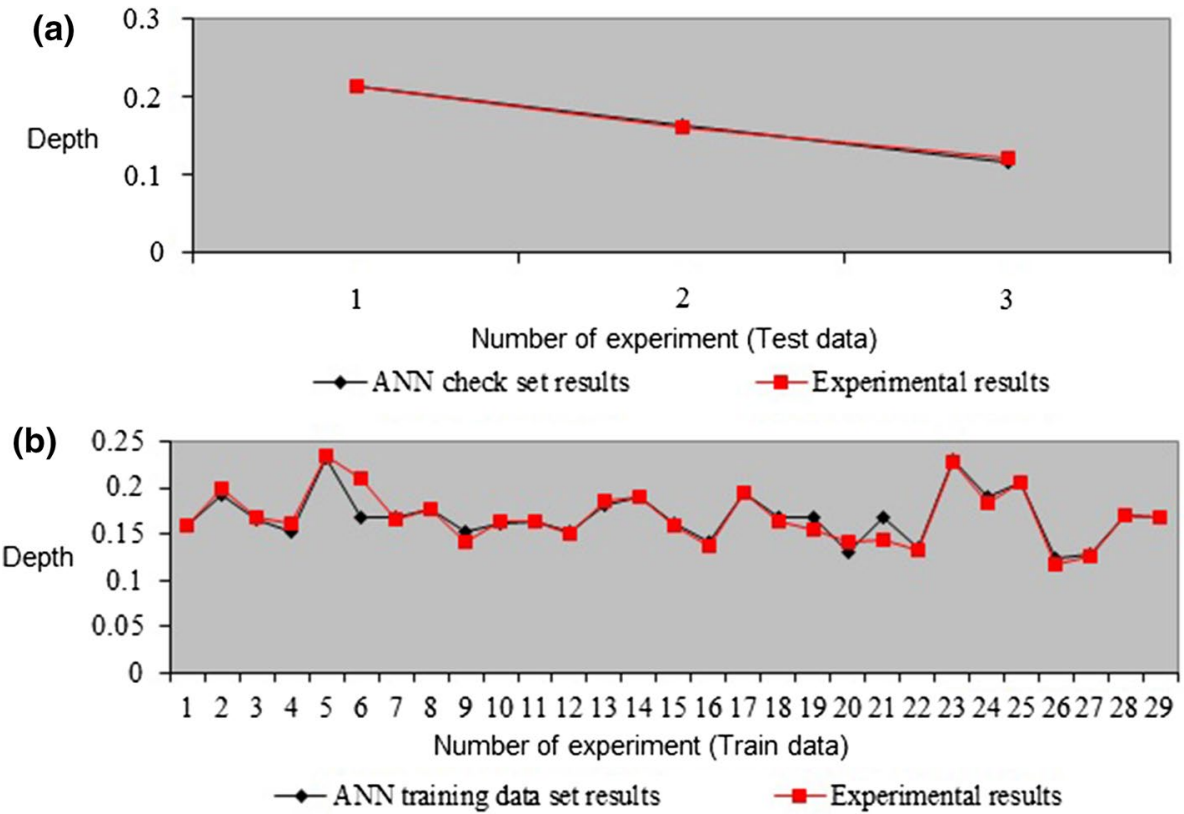

conclusion to consider reliable model, particularly ANN for predicting the responses satisfactorily under pre-cited process parameters in laser microgrooving operations.

\section{Optimization using genetic algorithm}

Genetic algorithm is a population-based search methodology for solving optimization problems stochastically that is based on the mechanism of natural selection that simulates the biological progression process developed from Darwin's theory of survival of the fittest (Vosniakos and Krimpenis 2002; Palanisamy et al. 2007). The mechanics of GAs is simple, involving copying of binary strings and the swapping of the binary strings. The simplicity of operation and computational efficiency are the two main attractions of the GA approach. In this systematic method, originally a set of possible solutions or chromosomes (normally as a string of genes) are randomly chosen, which serves as the generation (initial population). A basic GA comprises an encoding mechanism (ranks and signifies the chromosomes by means of a string of bits): a selection mechanism (choosing better fitness function value for minimization or maximization problems); a reproduction mechanism (pairing the chromosomes by probabilistically to reproduce new generation); a crossover mechanism (interchanging the information and genes between chromosomes); and a mutation mechanism (flipping a particular bit of a chromosome to obtain smart convergence). Each of these basic operators works on strings in a population only with simple bit changes. Figure 10 illustrates the flow of the way by which the GA technique operates when optimizing a problem.
The following points give a generic view of how GAs operate (Krimpenis et al. 2014): (1) a population of individuals (solutions) is created that consists of random individuals (initialization); (2) a function or a model (objective function) measures individual performance and determines their ability to survive and reproduce; (3) individuals are ranked (ranking) and the best/fittest individuals (according to a fitness function, which is an objective function transformation) are chosen (selection operator) to mate in pairs (crossover operator) and thus create new individuals and hence a whole new population. Every new individual (offspring) carries genetic characteristics from both parents. Slight mutation (mutation operator) occurs from generation to generation with given probability. Other population diversion operators, such as inversion, may be applied to the offspring; (4) in order to satisfy the criteria of the objective function, increasing competition among individuals leads to "survival of the fittest." This way, one generation after the other tends to have better genetic material (or characteristics) that help them survive. Individuals with best characteristics constitute the best solution to the problem; (5) this process continues in a repetitive manner until convergence criteria are met, i.e., the chromosomes have the best fitness or potential (optimum) solution for a specific problem is obtained. Immediately after the new generation is created, it is further assessed and checked through experimentation for the conformability and agreement (Shaik and Srinivas 2017).

In this work, MATLAB toolbox was utilized for optimization purpose by implementing GA technique with the aim to minimize the dimensional deviation. In laser microgrooving, multi-objective optimization problem can be formally defined in the following manner: 


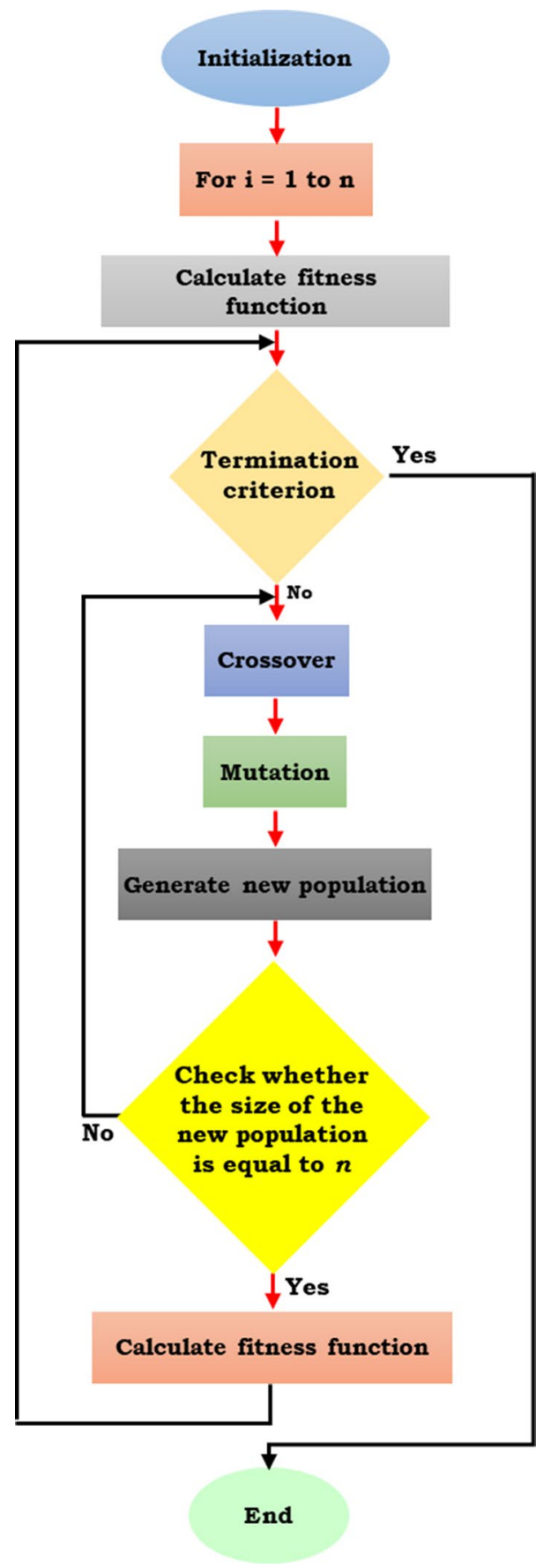

Fig. 10 Flowchart of GA-based algorithm

Find: input parameter $\left(X_{1}, X_{2}, X_{3}, X_{4}\right.$, and $\left.X_{5}\right)$

Minimize: $f\left(Y_{\mathrm{UWD}}, Y_{\mathrm{LWD}}\right.$, and $\left.Y_{\mathrm{DD}}\right)$

Allowable range of process parameters are: $0.4 \mathrm{kgf} / \mathrm{cm}^{2}$

$\leq$ air pressure $\left(X_{1}\right) \leq 2.0 \mathrm{kgf} / \mathrm{cm}^{2}, 14.5 \mathrm{Amp}$

$\leq$ lamp current $\left(X_{2}\right) \leq 24.5 \mathrm{Amp}, 1 \mathrm{kHz}$

$\leq$ pulse frequency $\left(X_{3}\right) \leq 5 \mathrm{kHz}, 0 \% \leq$ pulse width $\left(X_{4}\right)$

$\leq 8 \%$, and $12 \mathrm{~mm} / \mathrm{s} \leq$ cutting speed $\left(X_{5}\right) \leq 28 \mathrm{~mm} / \mathrm{s}$

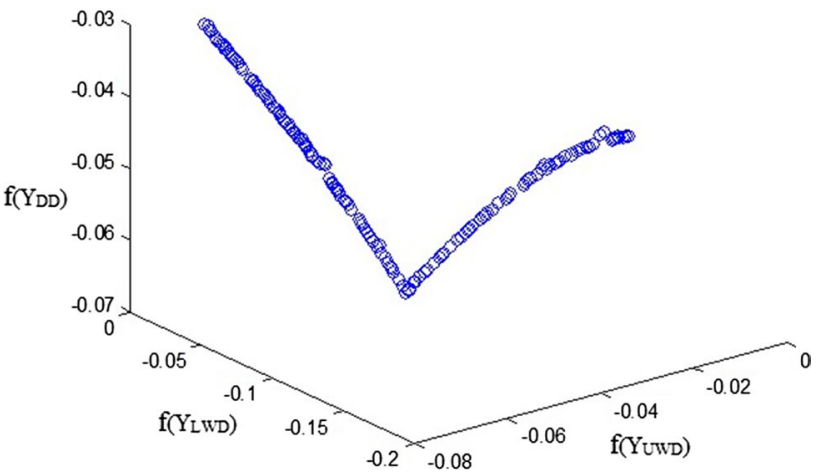

Fig. 11 GA-based multi-objective optimization results for upper width, lower width and depth

Here for mathematical descriptions, the objective functions $f\left(Y_{\mathrm{UWD}}\right), f\left(Y_{\mathrm{LWD}}\right)$ and $f\left(Y_{\mathrm{DD}}\right)$ are developed by RSM model in Eqs. (5)-(7) for deviation of upper width, lower width and depth, respectively. Figure 11 presents the optimization history, which aims to minimize the various dimensional deviations $\left(Y_{\mathrm{UPD}}, Y_{\mathrm{LWD}}, Y_{\mathrm{DD}}\right)$ of microgroove in the presence of algorithm-specific parameters of GA. In the present study, the critical (algorithm-specific) parameters are taken concerning population size of 250 , mutation rate of 0.10 , crossover rate of 1.0 , number of genes in each population member equal to 20 and maximum number of iterations equal to 500. By solving the optimization problem with GA, the optimized process parameters for minimizing microgrooving variables in laser machining of aluminum oxide $\left(\mathrm{Al}_{2} \mathrm{O}_{3}\right)$ ceramic material are pressure $1.2 \mathrm{kgf} / \mathrm{cm}^{2}$, lamp current $19.5 \mathrm{Amp}$, pulse frequency $4 \mathrm{kHz}$, pulse width $6 \%$, cutting speed $24 \mathrm{~mm} / \mathrm{s}$, with estimated deviations of upper width (UWD) of $-0.0278 \mathrm{~mm}$, lower width (LWD) of $0.0102 \mathrm{~mm}$ and depth (DD) of $-0.0308 \mathrm{~mm}$. The same is presented in Table 7. Figure 12 shows the microscopic image of laser microgroove produced at optimum parametric conditions.

Finally, an additional experiment is performed with the optimal configuration (suggested by GA) in order to compare this result with the ANN prediction model using same pre-cited optimum conditions, as listed in Table 8. As can be seen, the experimental result obtained by confirmation test matches the predicted results obtained by ANN and GA fairly well with a realistic degree of approximation. Therefore, the proposed approach (RSM-ANN-GA) can be effectively used to predict the various responses in laser microgrooving operation. The comparison results of ANNGA-experimental are presented in Fig. 13, which predicts that the upper width and depth are continuously negative, while lower width is constantly positive. 


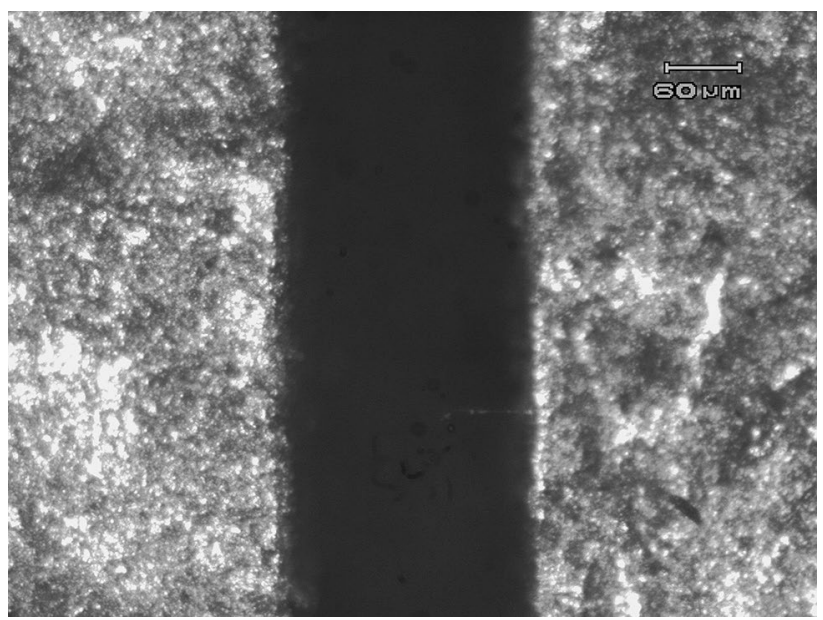

Fig. 12 Microscopic view of microgroove on aluminum oxide workpiece at optimum parametric conditions

\section{Conclusions}

In the present study, design of experiments (DOEs), response surface methodology (RSM), artificial neural network (ANN) and genetic algorithm (GA) have been applied for experimentation, mathematical modeling and multi-response optimization of laser microgrooving operation on aluminum oxide ceramic workpiece. Based on the series of experiment and analysis of results, the following conclusions are drawn.

- Experimentations have been successfully conducted using central composite design of RSM. The results are used to develop the mathematical model. The quadratic (second-order) mathematical model proposed for various dimensional deviations of microgroove using RSM is not only capable of achieving precise required dimension of microgrooves on aluminum oxide but also useful for predicting new experiments. The models are found to be adequate and statistically significant because of their higher $R^{2}$ value $89.1 \%$ for UWD, $91.7 \%$ for LWD, and $89.4 \%$ in case of DD), and $P$-value is lower than 0.05 .

- The experimental results are used to develop a multilayer feed-forward back propagation. The performance of predictive ANN model based on 5-8-8-3 architecture gave the minimum error $(\mathrm{MSE}=0.000099)$ and presented highly promising confidence with percentage of error less than $3 \%$ while compared with experimental result data sets.

- Optimization employing GA technique shows the optimal setting of process parameters in microgrooving operation of aluminum oxide by Nd:YAG laser treatment at lamp current of $19.5 \mathrm{Amp}$, pulse frequency of $4 \mathrm{kHz}$, pulse width $6 \%$, cutting speed of $24 \mathrm{~mm} / \mathrm{s}$ and air pressure of $1.2 \mathrm{kgf} / \mathrm{cm}^{2}$ with estimated minimal deviation of 


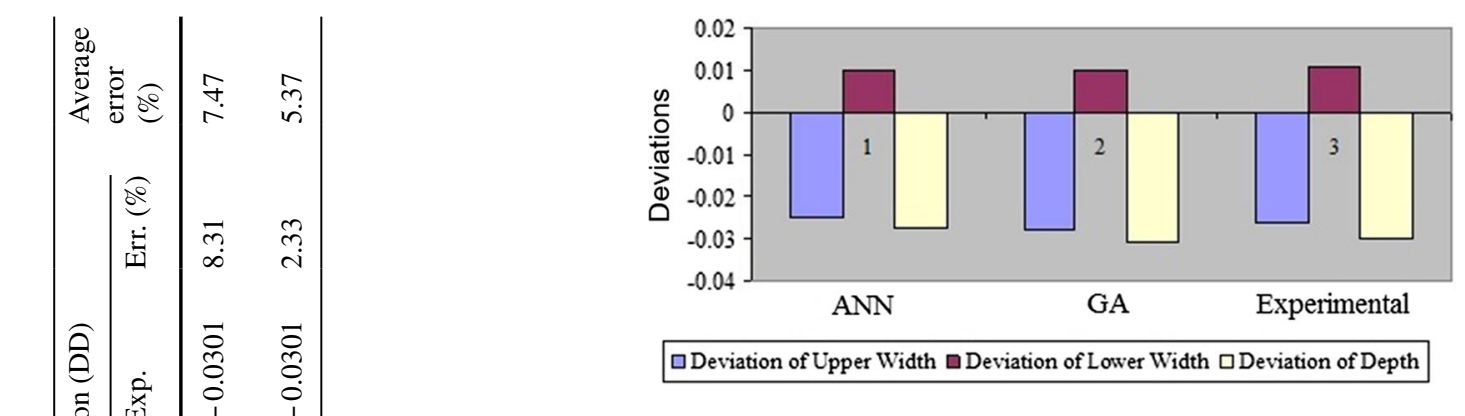

Fig. 13 Comparison of ANN, GA and experimental results

upper width $-0.0278 \mathrm{~mm}$, lower width of $0.0102 \mathrm{~mm}$ and depth of $-0.0308 \mathrm{~mm}$. The experimental result for the optimal setting shows that there is a considerable improvement in the laser microgrooving process.

- The present research based on GA, ANN and statistically multi-regression analysis (RSM) has demonstrated the ability to optimize and to accurately model the dimensional deviations of microgroove through advances in computer technology.

- The proposed multiple approaches (experimental, evolutional, statistic and stochastic) present reliable methodologies to improve laser microgrooving process, and they can be employed in real-time process monitoring, model predictive control and optimization in several machining processes.

- The outcome of the present research in the area of pulsed Nd:YAG laser micromachining of engineering ceramics can be effectively utilized by manufacturing engineers for the investigation and prediction of Nd:YAG laser process parametric settings for micromachining and microfabrication of different ceramic materials with intricate shape geometries.

- The present research study of pulsed Nd:YAG laser microgrooving operation on aluminum oxide ceramic will be useful as technological guidelines for further research in the area of laser microgrooving process of structural ceramics.

- This work will open up (1) future scope to study the cut surface quality with integrity for utilizing laser microgrooving more effectively and (2) challenging possibilities for exploring effective applications of laser technology for microgrooving of advanced ceramics in the field of high-precision microengineering.

Open Access This article is distributed under the terms of the Creative Commons Attribution 4.0 International License (http://creativecommons.org/licenses/by/4.0/), which permits unrestricted use, distribution, and reproduction in any medium, provided you give appropriate credit to the original author(s) and the source, provide a link to the Creative Commons license, and indicate if changes were made. 


\section{References}

Behera RR, Ghadai RK, Kalita K, Banerjee S (2016) Simultaneous prediction of delamination and surface roughness in drilling GFRP composite using ANN. Int J Plast Technol 20:424-450

Biswas R, Kuar AS, Biswas SK, Mitra S (2010) Artificial neural network modelling of $\mathrm{Nd}$ :YAG laser microdrilling on titanium nitride-alumina composite. Proc Inst Mech Eng Part B J Eng Manuf 224:473-482

Biswas R, Kuar AS, Mitra S (2015) Process optimization in Nd:YAG laser microdrilling of alumina-aluminium interpenetrating phase composite. J Mater Res Technol 4:323-332

Brihmat-Hamadi F, Amara EH, Lavisse L, Jouvard JM, Cicala E, Kellou $\mathrm{H}$ (2017) Surface laser marking optimization using an experimental design approach. Appl Phys A 123:230-1-13

Campanelli SL, Casalino G, Ludovico AD, Bonserio C (2013) An artificial neural network approach for the control of the laser milling process. Int J Adv Manuf Technol 66:1777-1784

Chryssolouris G (1991) Laser machining: theory and practice. Springer, New York

Ciurana J, Arias G, Ozel T (2009) Neural network modeling and particle swarm optimization (PSO) of process parameters in pulsed laser micromachining of hardened AISI H13 steel. Mater Manuf Process 24:358-368

Dahbi S, Ezzine L, Moussami HEL (2017) Modeling of cutting performances in turning process using artificial neural networks. Int J Eng Bus Manag 9:1-13

Darwish SMH, Saied MH, Ahmed N, Al-Ahmari AM (2017a) Laser beam micro-milling of micro-channels in aerospace alloys. Springer, Singapore

Darwish S, Ahmed N, Alahmari AM, Mufti NA (2017b) A study of micro-channel size and spatter dispersion for laser beam micromilling. J Mater Manuf Process 32:171-184

Das SR, Dhupal D, Kumar A (2015) Study of surface roughness and flank wear in hard turning of AISI 4140 steel with coated ceramic inserts. J Mech Sci Technol 29:4329-4340

Davim JP (2001) A note on the determination of optimal cutting conditions for surface finish obtained in turning using design of experiments. J Mater Process Technol 116:305-308

Dhar SK, Kuar AS, Mitra S (2008) An artificial neural network approach on parametric optimization of laser micro-machining of die-steel. Int J Adv Manuf Technol 39:39-46

Dhupal D, Doloi B, Bhattacharyya B (2007) Optimization of process parameters of $\mathrm{Nd}$ :YAG laser microgrooving of $\mathrm{Al}_{2} \mathrm{TiO}_{5}$ ceramic material by response surface methodology and artificial neural network algorithm. Proc Inst Mech Eng Part B J Eng Manuf 221:1341-1351

Dhupal D, Doloi B, Bhattacharyya B (2008a) Parametric analysis and optimization of Nd:YAG laser micro-grooving of aluminum titanate $\left(\mathrm{Al}_{2} \mathrm{TiO}_{5}\right)$ ceramics. Int $\mathrm{J}$ Adv Manuf Technol 36:883-893

Dhupal D, Doloi B, Bhattacharyya B (2008b) Pulsed Nd:YAG laser turning of micro-groove on aluminum oxide ceramic $\left(\mathrm{Al}_{2} \mathrm{O}_{3}\right)$. Int J Mach Tools Manuf 48:236-248

Dhupal D, Doloi B, Bhattacharyya B (2009) Modeling and optimization on Nd:YAG laser turned micro-grooving of cylindrical ceramic material. Opt Lasers Eng 47:917-925

Doloi B, Dhupal D, Bhattacharyya B (2007) Investigations into Nd:YAG laser micro-grooving on alumina. In: Proceedings of international conference on advanced manufacturing technologies, Durgapur, India, pp 125-135

Farooq K, Kar A (1998) Removal of laser-melted material with an assist gas. J Appl Phys 83:7467-7473

Giorleo L, Ceretti E, Giardini C (2016) Optimization of laser micromachining process for biomedical device fabrication. Int J Adv Manuf Technol 82:901-907
Hafezalkotob A, Hafezalkotob A (2016) Extended MULTIMOORA method based on Shannon entropy weight for materials selection. $\mathrm{J}$ Ind Eng Int 12:1-13

Hao X, Yan H, Han J, Yao C, He N (2018) Experimental research on pulse laser assisted micro turning of $\mathrm{ZrO}_{2}$ ceramic. Int $\mathrm{J}$ Nanomanuf 14:165-176

Haykin SO (2002) Neural networks: a comprehensive foundation. Pearson, Singapore

Kalita K, Shivakoti I, Ghadai RK (2017) Optimizing process parameters for laser beam micro-marking using genetic algorithm and particle swarm optimization. Mater Manuf Process 32:1101-1108

Khamel S, Ouelaa N, Bouacha K (2012) Analysis and prediction of tool wear, surface roughness and cutting forces in hard turning with CBN tool. J Mech Sci Technol 26:3605-3616

Kibria G, Doloi B, Bhattacharyya B (2010) Experimental analysis on $\mathrm{Nd}$ :YAG laser micro-turning of alumina ceramic. Int J Adv Manuf Technol 50:643-650

Kibria G, Doloi B, Bhattacharyya B (2012) Optimisation of Nd:YAG laser micro-turning process using response surface methodology. Int J Precis Technol 3:14-36

Kibria G, Doloi B, Bhattacharyya B (2013a) Predictive model and process parameters optimization of Nd:YAG laser micro-turning of ceramics. Int J Adv Manuf Technol 65:213-229

Kibria G, Doloi B, Bhattacharyya B (2013b) Investigation and analysis on pulsed $\mathrm{Nd}$ :YAG laser micro-turning process of aluminium oxide $\left(\mathrm{Al}_{2} \mathrm{O}_{3}\right)$ ceramic at various laser defocusing conditions. Int J Adv Manuf Technol 76:17-27

Kibria G, Doloi B, Bhattacharyya B (2014) Modelling and optimization of $\mathrm{Nd}$ :YAG laser micro-turning process during machining of aluminum oxide $\left(\mathrm{Al}_{2} \mathrm{O}_{3}\right)$ ceramics using response surface methodology and artificial neural network. Manuf Rev 1:1-8

Krimpenis AA, Fountas NA, Ntalianis I, Vaxevanidis NM (2014) CNC micromilling properties and optimization using genetic algorithm. Int J Adv Manuf Technol 70:157-171

Kuar AS, Biswas P, Mitra S, Biswas R (2008) Experimental investigation of $\mathrm{Nd}$ :YAG laser micro-grooving operation of alumina workpiece using RSM. Int J Mater Struct Integrity 1:355-370

Kuar AS, Acherjee B, Ganguly D, Mitra S (2012) Optimization of $\mathrm{Nd}$ :YAG laser parameters for microdrilling of alumina with multiquality characteristics via Grey-Taguchi method. Mater Manuf Process 27:329-336

Kumar A, Soota T, Kumar J Optimisation of wire-cut EDM process parameter by Grey-based response surface methodology. J Ind Eng Int. https://doi.org/10.1007/s40092-018-0264-8

Kumar V, Kumar V, Jangra KK (2015) An experimental analysis and optimization of machining rate and surface characteristics in WEDM of Monel-400 using RSM and desirability approach. J Ind Eng Int 11:297-307

Kuo CFJ, Huy QV, Dewantoro G, Luen LW (2012) Multi-objective optimization of laser-scribed micro grooves on AZO conductive thin film using Data Envelopment Analysis. Opt Laser Technol 44:1959-1970

Madić M, Radovanović M, Gostimirović M (2015) ANN modeling of kerf transfer in $\mathrm{CO}_{2}$ laser cutting and optimization of cutting parameters using Monte Carlo method. Int J Ind Eng Comput 6:33-42

Markopoulos AP, Georgiopoulos S, Manolakos DE (2016) On the use of back propagation and radial basis function neural networks in surface roughness prediction. J Ind Eng Int 12:389-400

Mishra S, Yadava V (2013) Modeling and optimization of laser beam percussion drilling of thin aluminum sheet. Opt Laser Technol 48:461-474

Moghaddam MA, Kolahan F (2016) Application of orthogonal array technique and particle swarm optimization approach in surface roughness modification when face milling AISI1045 steel parts. J Ind Eng Int 12:199-209 
Mohammed MK, Umer U, Al-Ahmari A (2017) Optimization of laser micro milling of alumina ceramic using radial basis functions and MOGA-II. Int J Adv Manuf Technol 91:2017-2029

Montgomery DC (2004) Design and analysis of experiments. Wiley, New York

Mukherjee R, Goswami D, Chakraborty S (2013) Parametric optimization of Nd:YAG laser beam machining process using artificial bee colony algorithm. J Ind Eng. https://doi.org/10.1155/2013/570250

Nandi S, Kuar AS (2015) Parametric optimisation of Nd:YAG laser micro-drilling of alumina using NSGA II. Int J Mach Mach Mater $17: 1-21$

Olsen FO, Alting L (1995) Pulsed laser materials processing, ND-YAG versus $\mathrm{CO}_{2}$ lasers. CIRP Ann Manuf Technol 44:141-145

Palanisamy P, Rajendran I, Shanmugasundaram S (2007) Optimization of machining parameters using genetic algorithm and experimental validation for end-milling operations. Int J Adv Manuf Technol 32:644-655

Peter J, Doloi B, Bhattacharyya B (2013) Analysis of Nd:YAG laser marking characteristics on alumina ceramics. J Inst Eng (India) Ser C 94:287-292

Qian X, Ma Y, Feng H Collaboration space division in collaborative product development based on a genetic algorithm. J Ind Eng Int. https://doi.org/10.1007/s40092-018-0257-7

Shaik JH, Srinivas J (2017) Optimal selection of operating parameters in end milling of Al-6061 work materials using multi-objective approach. Mech Adv Mater Mod Process 3:1-11
Shivade AS, Shinde VD (2014) Multi-objective optimization in WEDM of D3 tool steel using integrated approach of Taguchi method \& Grey relational analysis. J Ind Eng Int 10:149-162

Shivakoti I, Pradhan BB, Diyaley S, Ghadai RK, Kalita K (2017) Fuzzy TOPSIS-based selection of laser beam micro-marking process parameters. Arab J Sci Eng 42:4825-4831

Somashekhar KP, Ramachandran N, Mathew J (2010) Optimization of material removal rate in micro-EDM using artificial neural network and genetic algorithms. Mater Manuf Processes 25:467-475

Vosniakos GC, Krimpenis A (2002) Optimisation of multiple tool CNC rough machining of a hemisphere as a genetic algorithm paradigm application. Int J Adv Manuf Technol 20:727-734

Wang W, Chen J, Li D, Feng D, Tu Y (2016) Modelling and optimisation of a femtosecond laser micro-machining process for microhole array products. Int J Adv Manuf Technol 82:1293-1303

Yang K, Xia Y, Li L, He N, Zhang Y, Zhang T, Wang Y (2018) Experimental study on hybrid machining of laser irradiation and grinding for sharpening of a CVD diamond micro-milling tool. Int J Adv Manuf Technol 96:327-336

Zhang G, Jiang C, Zhang S, Wang Y, Chen X, Yu L (2015) An experimental investigation of laser assisted drilling process. Mater Res Innov 19:S8-889-S8-894 